Original Article

\title{
Curcumin Down-Regulates CD44 Marker Expresion and Inhibits the Growth of Tumorsphere in 3D Culture Condition of Gastric Cancer Cell line MKN45
}

\author{
Nguyen Phu Hung ${ }^{1, *}$, Le Thi Thanh Huong ${ }^{1}$, Nguyen Trung Thanh ${ }^{2}$ \\ ${ }^{I}$ Thai Nguyen University of Sciences, Thai Nguyen University, \\ Z115 street, Tan Thinh ward, Thai Nguyen city, Thai Nguyen province, Vietnam \\ ${ }^{2}$ VNU University of Science, 334 Nguyen Trai, Hanoi, Vietnam
}

Received 10 May 2020

Revised 28 August 2020; Accepted 30 August 2020

\begin{abstract}
Stomach cancer is the fifth most common cancer in the world. In Vietnam, the number of deaths by stomach cancer ranks third after lung cancer and liver cancer. Finding naturally occurring compounds that can effectively inhibit tumor is very important in the treatment of cancer, especially for developing countries as Vietnam. This study showed that curcumin has ability to inhibit stomach cancer evaluated on a 3D culture model. This is a model that has many advantages compared to the traditional model (2D) for screening of new drugs. Research results show that curcumin had significantly reduced the expression of CD44 stem cell marker on the gastric cancer. Curcumin inhibited the formation of tumorsphere in non-adhering culture conditions 3D. In addition, curcumin reduced the size of the tumorspheres compared to the control.
\end{abstract}

Keywords: gastric cancer stem cell, cancer stem cell marker, curcumin, 3D culture.

\footnotetext{
* Corresponding author.

Email address: hungnguyenphu@tnus.edu.vn

https://doi.org/10.25073/2588-1140/vnunst.5075
} 


\title{
Curcumin điều hòa giảm sự biểu hiện marker tế bào gốc ung thư CD44 và ức chế sự sinh trưởng của các tumorsphere trong điều kiện nuôi cấy 3D ở dòng tế bào ung thư dạ dày MKN45
}

\author{
Nguyễn Phú Hùng ${ }^{1, *}$, Lê Thị Thanh Hương ${ }^{1}$, Nguyễn Trung Thành ${ }^{2}$ \\ ${ }^{1}$ Truòng Đại học Khoa học, Đại học Thái Nguyên, Việt Nam \\ ${ }^{2}$ Truò̀ng Đại học Khoa học Tự nhiên, Đại học Quốc gia Hà Nội, 334 Nguyễn Trãi, Hà Nội, Việt Nam \\ Nhận ngày 10 tháng 5 năm 2020 \\ Chỉnh sửa ngày 28 tháng 8 năm 2020; Chấp nhận đăng ngày 30 tháng 8 năm 2020
}

\begin{abstract}
Tóm tắt: Ung thư dạ dày là dạng ung thư phổ biến thứ năm trên thế giới. Tại Việt Nam, số trường hợp mắc và tử vong vì ung thư dạ dày đứng hàng thứ 3 chỉ sau ung thư phổi và ung thư gan. Nghiên cứu tìm kiếm các hợp chất có nguồn gốc từ tự nhiên có khả năng ức chể ung thư hiệu quả và chi phí thấp có ý nghĩa đặc biệt quan trọng trong việc điều trị ung thư, đặc biệt là đối với các nước đang phát triển như Việt Nam. Trong nghiên cứu này, khả năng ức chế ung thư dạ dày của curcumin được đánh giá trên mô hình nuôi cấy 3D. Đây là một mô hình có nhiều ưu việt so với mô hình truyền thống (2D) trong việc sàng lọc thuốc mới. Kết quả nghiên cứu cho thấy, curcumin đã điều hòa giảm mạnh các tế bào biểu hiện marker tế bào gốc $\mathrm{CD} 44$ của ung thư dạ dày. Mặt khác, curcumin đã ức chế sự hình thành các khối cầu ung thư (tumorsphere) trong điều kiện nuôi cấy không bám dính trong mô hình nuôi cấy 3D. Bên cạnh đó, curcumin đã làm giảm rõ rệt kích thước của các khối cầu ung thư so với đối chứng.
\end{abstract}

Tù khóa: tế bào gốc ung thư dạ dày, marker tế bào gốc ung thư, curcumin, nuôi cấy 3D.

\section{Mở đầu}

Ung thư dạ dày là nguyên nhân đứng hàng thứ năm gây tử vong liên quan đến ung thư trên toàn thế giới. Theo thống kê mới nhất của $\mathrm{Co}$ quan nghiên cứu ung thư quốc tế (IARC), ung thư dạ dày có tỷ lệ mắc và tỷ lệ chết đứng hàng thứ ba. Các nghiên cứu gần đây chỉ ra rằng, trong khối u dạ dày có sự tồn tại của một quần thể các tế bào gốc ung thư, các tế bào này có khả năng phân chia, biệt hóa và tái tạo khối u không giới hạn [1]. Đồng thời, các tế bào gốc ung thư cũng được chỉ ra là nguyên nhân dẫn tới sự kháng thuốc điều trị, cũng như khả năng tái phát và di

\footnotetext{
* Tác giả liên hệ.

Địa chỉ email: hungnguyenphu@tnus.edu.vn
}

https://doi.org/10.25073/2588-1140/vnunst.5075 căn [2]. Các liệu pháp nhắm mục tiêu là tế bào gốc ung thư được xem như một cách tiếp cận đầy hứa hẹn để cải thiện kết quả điều trị cho các bệnh nhân ung thư nói chung và ung thư dạ dày nói riêng [3].

Curcumin là một trong những hợp chất thiên nhiên được sử dụng nhiều trong y học. Curcumin được người Ấn Độ sử dụng với mật ong dùng cho phụ nữ sau sinh [4]. Các nghiên cứu đã chỉ ra rằng, curcumin có khả năng ức chế ung thư vú, ung thư đại tràng, ung thư máu, ung thư phổi, ung thư buồng trứng [5]. Curcumin được dùng phổ biến trong điều trị một số bệnh về dạ dày như viêm dạ dày, loét dạ dày. Báo cáo gần đây cũng 
chỉ ra rằng, curcumin có khả năng ức chế tế bào ung thư dạ dày dòng SGC7901 [6]. Mặt khác, một số thử nghiệm khả năng kìm hãm sự phát triển ung thư dạ dày ở người bởi curcumin cũng đã được nghiên cứu. Các thử nghiệm lâm sàng cho thấy rằng, curcumin là một tác nhân đầy hứa hẹn đối với liệu pháp ung thư [7]. Đáng chú ý, curcumin đã được xác định là có khả năng ức chế các tế bào gốc ung thư trong các dạng ung thư khác nhau gồm ung thư đại tràng, ung thư vú, ung thư não, ung thư tụy tạng và ung thư đầu cổ [8]. Đối với ung thư dạ dày, các nghiên cứu về khả năng ức chế ung thư của curcumin còn rất hạn chế và khả năng tác động của curcumin lên các tế bào gốc ung thư dạ dày cần được làm sáng tỏ. Các tế bào gốc ung thư được nhận diện, phân biệt với các tể bào khác trong cùng một khối thông qua marker đặc trưng trên bề mặt của tế bào, điển hình như CD44, CD133, CD166 hoặc các enzyme nội bào như ALDH [9]. Đối với ung thư da dày, CD44 đã được chứng minh là marker đặc trưng của tế bào gốc ung thư dạ dày [10]. Marker này biểu hiện trên bề mặt của tế bào ung thư và là thụ thể của acid hyaluronic. Sự tương tác giữa acid hyaluronic với CD44 liên quan mật thiết tới sự phát sinh ung thư cũng như quá trình di căn của tế bào [11]. Làm giảm sự biểu hiện của marker này cũng đã được chứng minh là dẫn tới kìm hãm sự tăng sinh tế bào ung thư [12].

\section{Vật liệu và phương pháp nghiên cứu}

\subsection{Vật liệu, hóa chất}

Dòng tế bào ung thư da dày MKN45 có nguồn gốc từ ATCC, nhận được từ phòng thí nghiệm Inserm U1053, Viện Sức khỏe và Nghiên cứu Y học Quốc gia Pháp.

Curcumin được chiết xuất từ cây Nghệ, do Sigma Aldrick (Pháp) cung cấp, có mã số sản phẩm là $\mathrm{C} 1386$. Kháng thể CD44 gắn chất phát quan PE (Phycoerythrin) do BD Biosciences cung cấp. Môi trường nuôi cấy RPMI1640 và DMEMF12 được cung cấp bởi Invitrogen. Yếu tố tăng trưởng biểu mô (EGF), yếu tố tăng trưởng nguyên bào sợi (FGF) do Sigma Aldrick (Pháp) cung cấp.
2.2. Xủ lý tế bào MKN45 với curcumin trong điều kiện nuôi cấy bám dính (2D)

Các tế bào ung thư dạ dày MKN45 được nuôi cấy trong đĩa 12 giếng, mỗi giếng được bổ sung $2 \mathrm{ml}$ môi trường RPMI1640 chứa $10 \%$ FBS và $1 \%$ kháng sinh $\mathrm{P} / \mathrm{S}$. Lượng tế bào được cho vào trong mỗi giếng nuôi cấy là 30.000 tế bào. Các tế bào được nuôi cấy trong điều kiện nhiệt độ là $37{ }^{\circ} \mathrm{C}, 5 \% \mathrm{CO}_{2}$. Sau $24 \mathrm{~h}$ nuôi cấy, các tế bào đã bám dính trên bề mặt đĩa, các tế bào được xử lý với curcumin ở các nồng độ $0 \mu \mathrm{M}$ (đối chứng), $5 \mu \mathrm{M}, 10 \mu \mathrm{M}$ và $20 \mu \mathrm{M}$ trong $48 \mathrm{~h}$.

\subsection{Phân tích sự biểu hiện marker CD44}

Các tế bào sau khi được xử lý hoặc không xử lý (đối chứng) với curcumin ở các nồng độ khác nhau được thu nhận bằng ly tâm ở 1.300 vòng trong 3 phút và rửa 2 lần với đệm $\mathrm{PBS} 1 \mathrm{X}$. Tiếp theo, tế bào được nhuộm trực tiếp với kháng thể đơn dòng kháng CD44-PE, theo tỷ lệ 1:50, ở nhiệt độ $4{ }^{\circ} \mathrm{C}$ trong 15 phút. Tế bào được rửa 2 lần với $\mathrm{PBS} 1 \mathrm{X}$ bằng phương pháp ly tâm, ở lần rửa thứ 2 tế bào được rửa trong đệm $\mathrm{PBS}$ chứa chất nhuộm nhân tế bào DAPI (4,6-Diamidino2-phenylindole do Sigma cung cấp) nồng độ $10 \mu \mathrm{g} / \mathrm{ml}$. Các tế bào sau khi được ủ với kháng thể đơn dòng CD44-PE sẽ được đưa lên lam kính và được quan sát ở độ phóng đại 200 và 400 lần dưới kính hiển hiển vi huỳnh quang NIKON, ở phin lọc tương ứng với chất phát quang DAPI và PE.

Tỷ lệ tế bào biểu hiện marker CD44 được tính bằng tỷ số tế bào phát quang màu đỏ với thuốc nhuộm PE gắn trên kháng thể CD44 trên tổng số nhân tế bào bắt màu với thuốc nhuộm DAPI.

\subsection{Phân tích sự biểu hiện CD44 bằng Flow cytometry}

Thu nhận các tế bào sau khi xử lý hoặc không xử lý với curcumin. Sau đó, các tế bào được ủ với kháng thể đơn dòng CD44-PE trong 10 phút và được rửa 2 lần bằng đệm $\mathrm{PBS} 1 \mathrm{X}$. Sau đó, các tế bào được phân tích bằng hệ thống Flow cytometry BD Accuri C6 (BD - Biosciences). 
10.000 dữ kiện được ghi lại và xử lý bằng phần mềm chuyên dụng của hệ thống.

Dữ liệu được thống kê và phân tích bằng phần mềm Graphpab Prism 5.0, sử dụng kiểm định Mann-Whitney.

\subsection{Nuôi cấy và đánh giá tác động của curcumin lên các tumorsphere trong điều kiện $3 D$}

\subsubsection{Nuôi cấy tumorsphere 3D}

Quy trình nuôi cấy được tiến hành theo nghiên cứu trước đó [13]. Nuôi cấy các tế bào ung thư dạ dày MKN45 với mật độ 2.000 tế bào/giếng nuôi cấy diện tích $3,8 \mathrm{~cm}^{2}$ bề mặt không bám dính để hình thành lên tumorsphere, trong môi trường DMEMF12/Glutamax có bổ sung EGF 20ng/ml, FGF 20ng/ml, glucose 0,3\%, insulin $5 \mu \mathrm{g} / \mathrm{ml}$ ở $37^{\circ} \mathrm{C}, 5 \% \mathrm{CO}_{2}$. Sau 2 ngày nuôi cấy, các tế bào có đặc tính của tế bào gốc phân chia tạo thành các cụm từ $3-5$ tế bào, lơ lửng trong môi trường nuôi cấy được gọi là các tumorsphere. Các tumorsphere này tiếp tục tăng trưởng theo thời gian và có dạng hình cầu [14].

2.5.2. Đánh giá ảnh hưởng của curcumin lên sự hình thành tumorsphere

Để đánh giá ảnh hưởng của curcumin lên sự hình thành tumorsphere, môi trường nuôi cấy chứa curcumin ở các nồng độ khác nhau (từ 0 đến $20 \mu \mathrm{M}$ ) được sử dụng ngay từ đầu trong quá trình nuôi cấy hình thành tumorsphere. Số lượng tumorsphere được hình thành sau 5 ngày sẽ được đếm và chụp ảnh dưới kính hiển vi soi ngược NIKON Ts2 ở độ phóng đại 200 lần.

2.5.3. Đánh giá ảnh hưởng của curcumin lên sự tăng trưởng về kích thước của tumorsphere

Sau 5 ngày nuôi cấy (như trình bày trong mục 2.5.1), các tumorsphere được hình thành. Các tumorsphere được thu nhận bằng li tâm 1.300 vòng/phút trong 5 phút và được chuyển sang đĩa nuôi cấy không bám dính loại 96 giếng với mật độ 100 sphere/giếng. Tiếp theo, các sphere được xử lý với curcumin ở nồng độ từ 0 $-20 \mu \mathrm{M}$. Sự thay đổi về hình thái và số lượng được quan sát và chụp ảnh dưới kính hiển vi soi ngược. Những thay đồi về kích thước được phân tích bằng việc sử dụng phần mền ImagJ. Dữ liệu được thống kê và phân tích bằng phần mềm Graphpad Prism 5.0, sử dụng kiểm định MannWhitney.

\section{Kết quả và thảo luận}

\subsection{Curcumin điều hoà giảm sụ biểu hiện của marker tế bào gốc ung thu da dày CD44}

Các nghiên cứu trước đây của Takaishi và nhóm nghiên cứu của chúng tôi đã xác định CD44 là marker của tế bào gốc ung thư dạ dày [15], [16]. Trong nghiên cứu này, các tế bào MKN45 được xử lý với curcumin để đánh giá ảnh hưởng lển sự biểu hiện của CD44 bằng miễn dịch huỳnh quang và Flow cytometry. Kết quả được chỉ ra trong Hình $1 \mathrm{~A}$ cho thấy, trong điều kiện nuôi cấy bám dính, ở nồng độ $5 \mu \mathrm{M}$, curcumin không làm thay đổi mức độ biểu hiện CD44 của tế bào. Tuy nhiên, ở các nồng độ cao hơn là $10 \mu \mathrm{M}$ và $20 \mu \mathrm{M}$, sự thay đổi về số lượng tế bào biểu hiện CD44 là rất khác biệt so với đối chứng. Để khẳng định lại kết quả phân tích miễn dịch huỳnh quang cũng như định lượng chính xác được tỷ lệ các tế bào biểu lộ CD44, chúng tôi đã sử dụng phương pháp Flow cytometry (Hình $1 \mathrm{~B}$ và Hình $1 \mathrm{C}$ ). Kết quả phân tích bằng Flow cytometry đã cho thấy, ở nồng độ $10 \mu \mathrm{M}$ tỷ lệ tế bào biểu lộ marker CD44 đã giảm xuống còn xấp xỉ $60 \%$ so với đối chứng. Đặc biệt ở nồng độ cao $20 \mu \mathrm{M}$ curcumin đã tác động mạnh lên sự biểu hiện CD44, chỉ còn khoảng $7 \%$ các tế bào biểu hiện CD44 so với đối chứng. Trái ngược lại, ở nồng độ thấp $5 \mu \mathrm{M}$, không tìm thấy sự khác biệt về sự biểu hiện của CD44 giữa quần thể tế bào được xử lý với quần thể tế bào đối chứng. Kết quả này hoàn toàn phù hợp với phân tích miễn dịch huỳnh quang trong Hình $1 \mathrm{~A}$.

Các nghiên cứu gần đây về sàng lọc và phát triển các thuốc nhắm đích tế bào gốc ung thư đều tiến hành đánh giá khả năng điểu hòa giảm sự biểu hiện marker của tế bào gốc trong các quần thể tế bào ung thư. Nghiên cứu của Quarni và cộng sự gần đây khi xử lý tế bào ung thư đại tràng với mithramycin $\mathrm{A}$ đã chỉ ra rằng, thuốc này đã làm giảm rõ rệt quần thể tế bào gốc ung thư biểu hiện marker ALDH và marker Lg5 [17]. 
Một công bố gần gần đây của chúng tôi trên các dòng tế bào ung thư dạ dày và các tế bào ung thư dạ dày phân lập từ khối u đầu tiên của bệnh nhân đã chỉ chứng minh được all trans retinoic acid (ATRA) có khả năng ức chế mạnh sự phát triển của tế bào gốc ung thư trong cả mô hình in vitro và in vivo. Ở đó, ATRA đã làm giảm rõ rệt sự biểu hiện của 2 marker tế bào gốc ung thư dạ dày là $\mathrm{ALDH}$ và $\mathrm{CD} 44$ [13]

A
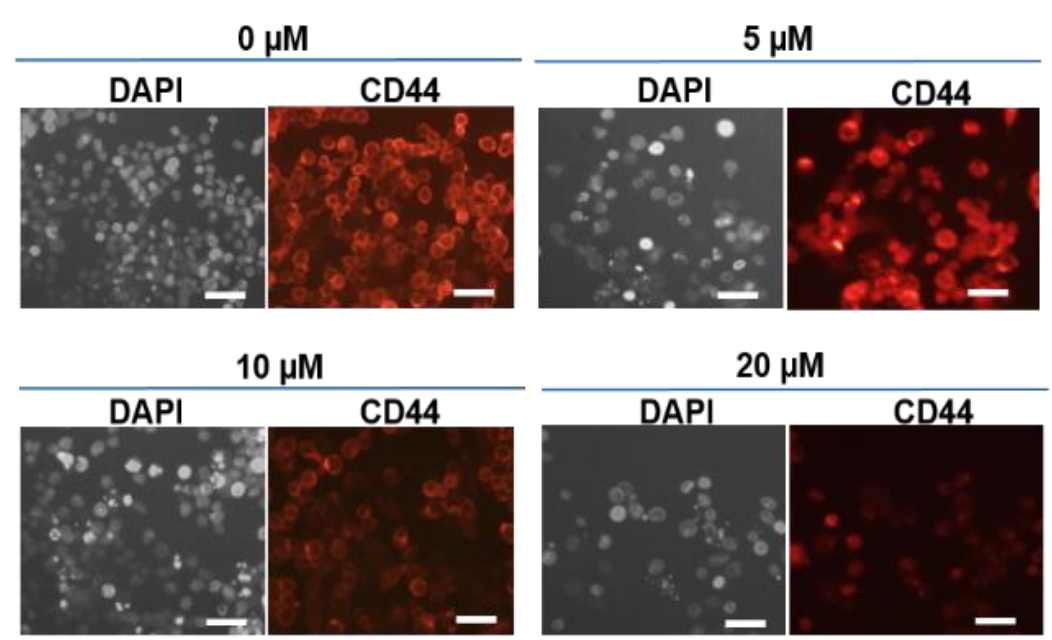

B
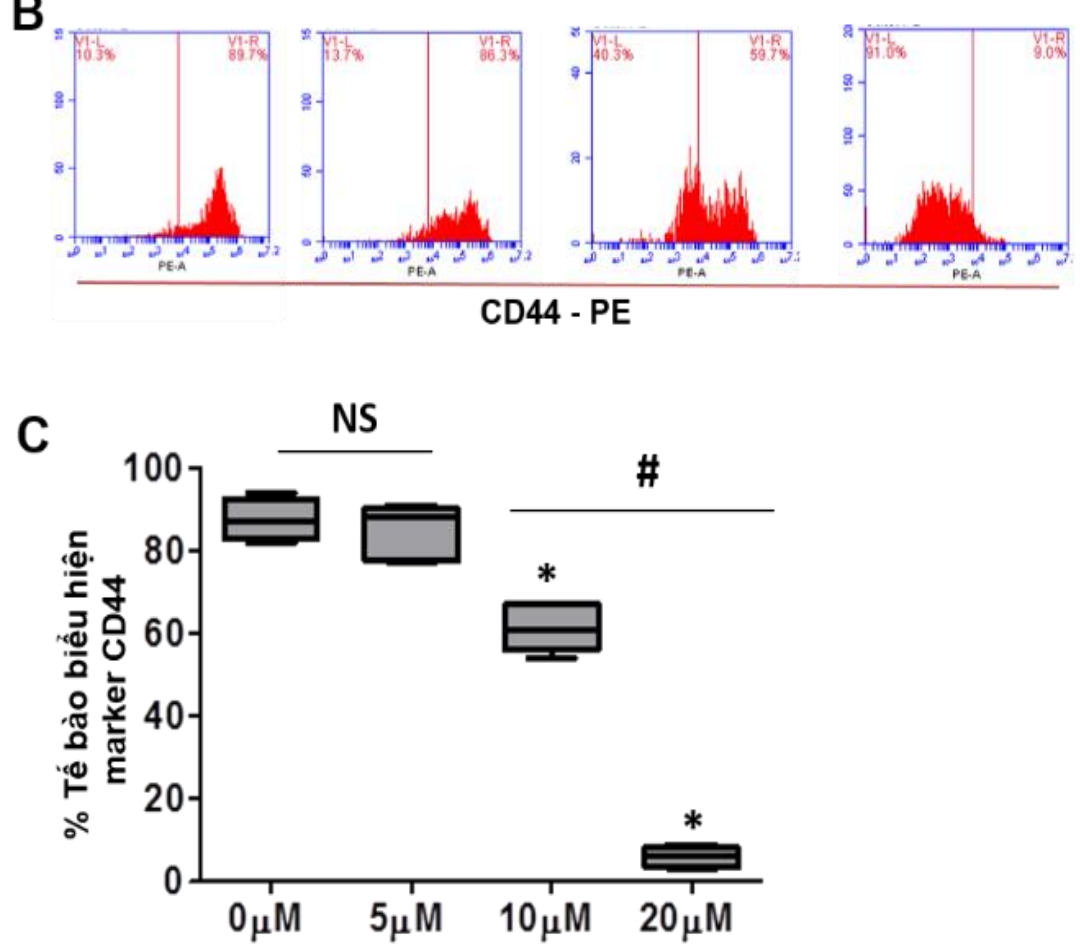

Hình 1. Ảnh hưởng của curcumin lên sự biểu hiện marker CD44: Nhân tế bào được nhuộm với DAPI (ảnh đen trắng), các tế bào biểu hiện marker $\mathrm{CD} 44$ có màu đỏ $(\mathrm{A})$, mức độ biểu hiện $\mathrm{CD} 44$ bằng phân tích Flow cytometry $(\mathrm{B}$ và $\mathrm{C}) ; \mathrm{n}=5,{ }^{*} \mathrm{p} \leq 0,0001$ so với đối chứng $(0 \mu \mathrm{M}), \# \mathrm{p} \leq 0,05$. NS (not significant): không có sự khác biệt. Thang đo $50 \mu \mathrm{m}$. 
Một số thử nghiệm lâm sàng về các thuốc mới nhắm thẳng vào đích là các marker bề mặt CD44 của tế bào ung thư vú hay marker CD44V4 ở ung thư phổi không tế bào nhỏ hay CD123 ở tế bào gốc ung thư buồng trứng [18]. Điều này cho thấy rằng, các tế bào gốc với những marker đặc trưng đang trở thành một đích tiếp cận đầy tiềm năng trong việc phát triển thuốc chống ung thư hiện nay. Trong nghiên cứu này của chúng tôi, lần đầu tiên chúng tôi xác định được curcumin đã điều hòa giảm rõ rệt các tế bào gốc ung thư biểu hiện marker CD44. Đây là cơ sở quan trọng khẳng định, curcumin là chất tiềm năng trong nhắm đích ung thư dạ dày.

\subsection{Curcumin ức chế sụ hình thành và tăng truơng của các tumorsphere $3 D$}

Sự hình thành các tumorsphere trong điều kiện nuôi cấy 3D là một trong những đặc tính đặc biệt quan trọng của các tể bào gốc ung thư. Tumorsphere là khối cầu được hình thành lên từ sự phân chia của một tế bào ung thư ban đầu có đặc tính của một tế bào gốc.

Trong nghiên cứu này, chúng tôi tiến hành nuôi cấy tế bào riêng rẽ (không phải là khối tế bào) trong môi trường 3D không bám dính như mô tả trong mục 2.5.1 có bổ sung hoặc không bổ sung curcumin để đánh giá tác động của thuốc này lên sự hình thành và tăng trưởng của các tumorsphere.

Kết quả trình bày trong Hình $2 \mathrm{~A}$ và $2 \mathrm{~B}$ cho thấy rằng, curcumin tác động mạnh lên số lượng các tumorsphere được hình thành theo chiều tăng của nồng độ xử lý. Ngay ở nồng độ $5 \mu \mathrm{M}$, mặc dù trong điều kiện nuôi cấy $2 \mathrm{D}$, curcumin đã không điều hòa giảm sự biểu hiện của marker CD44 nhưng trong điều kiện nuôi cấy 3D đã cho thấy, curcumin đã làm giảm đáng kể số lượng các tumorsphere được hình thành từ các tế bào gốc. Đặc biệt, ở nồng độ cao từ $10 \mu \mathrm{M}$, tỷ lệ tumorsphere hình thành chỉ bằng khoảng $1 / 3$ so với đối chứng và không thấy có sự hình thành các turmosphere khi tế bào bị xử lý với curcumin ở nồng độ cao $20 \mu \mathrm{M}$.

Bên cạnh việc ảnh hưởng lên sự hình thành các tumorsphere, chúng tôi còn nhận thấy rằng, curcumin đã ảnh hưởng rất rõ rệt lên kích thước đối với các tumorsphere được hình thành. Kết quả được trình bày trong Hình $2 \mathrm{~A}$ và Hình $2 \mathrm{C}$ đã cho thấy, kích thước của các tumorsphere được tạo ra trong môi trường có bổ sung curcumin ở nồng độ từ $5-20 \mu \mathrm{M}$ so với các tumorsphere đối chứng $(0 \mu \mathrm{M})$ có sự khác biệt. Kích thước tumorsphere giảm mạnh theo chiều tăng của nồng độ curcumin. Đáng chú ý, ở nồng độ thấp $5 \mu \mathrm{M}$, curcumin không ảnh hưởng lên số lượng tumorsphere được hình thành (Hình $2 \mathrm{~A}$ và Hình 2B) nhưng đã tác động đáng kể lên kích thước của các tumorspher, làm giảm trung bình $20 \%$ kích thước so với đối chứng.

Công bố gần đây của Laszlo và cộng sự trên đối tượng là ung thư trung biểu mô màng phổi ác tính đã chỉ ra rằng, chất ức chế $\mathrm{FAK}$ inhibitor $\mathrm{BI}$ 853520 không chỉ ức chế sự tăng sinh của các tế bào ung thư trong điều kiện nuôi cấy $2 \mathrm{D}$ mà nó còn làm giảm cả số lượng và kích thước của các tumorsphere 3D [19]. Trong một nghiên cứu trước đó trên các tế bào ung thư dạ dày, chúng tôi đã nhận thấy, ATRA không chỉ kìm hãm sự tạo các turmosphere trong điều kiện nuôi cấy 3D mà nó đã ức chế sự tăng trưởng về mặt kích thước của chúng [13]. Tương tự như vậy, Courtois và cộng sự đã báo cáo rằng, metformin là loại thuốc có khả năng áp chế hiệu quả các tế bào gốc ung thư dạ dày. Metformin không chỉ làm giảm số lượng tế bào gốc biểu hiện marker CD44 trong quần thể tế bào ung thư dạ dày AGS, MKN45 mà nó còn giảm rõ rệt kích thước các tumorsphere được hình thành trong điều kiện nuôi cấy 3D [20]. Như vậy, trong nghiên cứu này, chúng tôi đã xác định được curcumin có đặc tính của một thuốc ức chế đặc tính của tế bào gốc ung thư dạ dày.

\subsection{Curcumin ảnh huởng lên số luợng và kích thước của các tumorsphere đã được hình thành}

Tumorsphere là một khối cầu gồm hàng trăm các tế bào kết dính với nhau, trong đó các tế bào bề mặt có khả năng phân chia mạnh và các tế bào bên trong lõi là các tế bào chết hoặc kém phân chia. Chính vì vậy, tumorsphere được đánh giá có sự tương đồng nhất định đối với khối u trong in vivo. Trên cơ sở đó, chúng tôi đã tiến hành đánh 
A

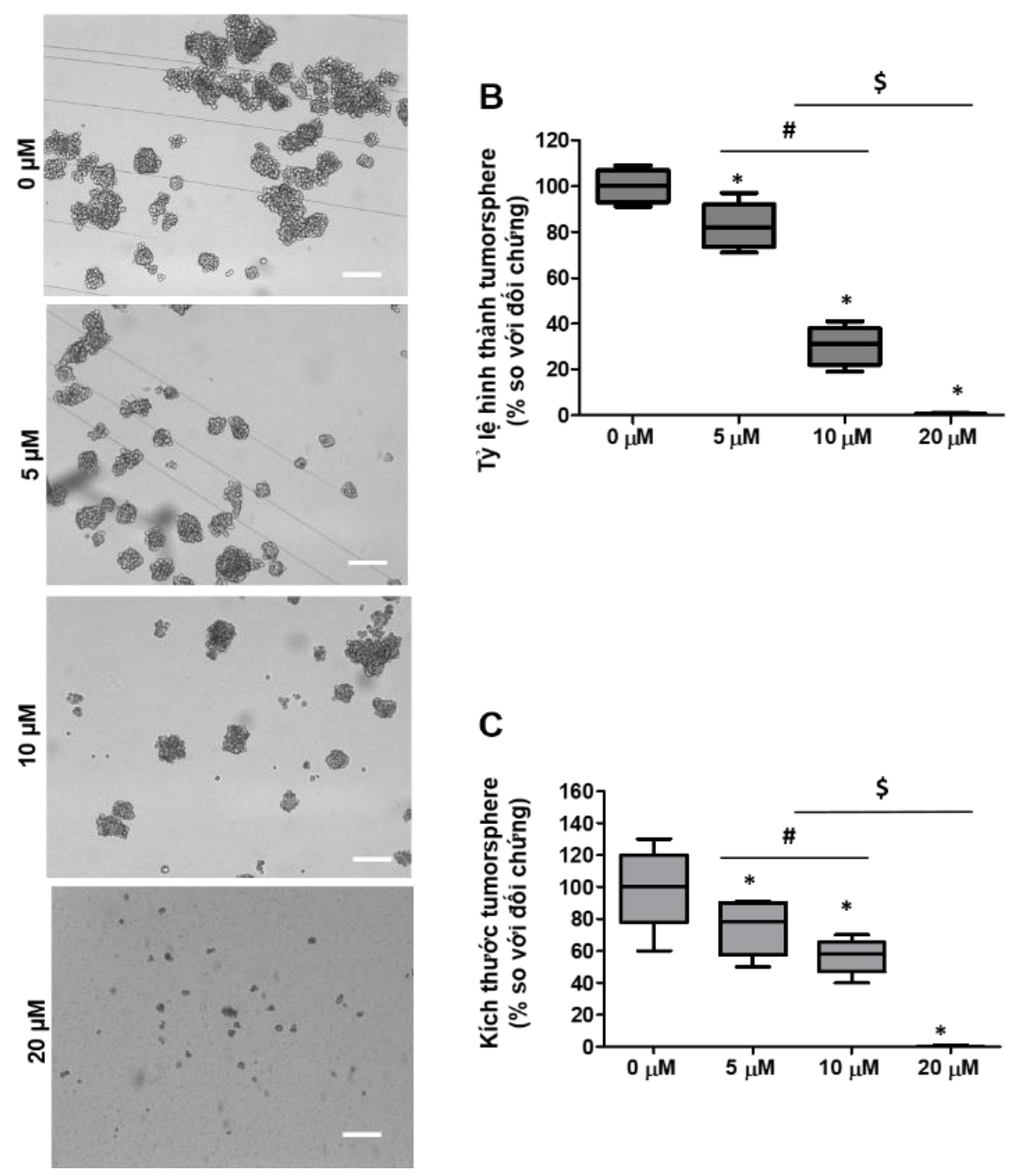

Hình 2. Ảnh hưởng của curcumin lên sự hình thành các tumorsphere của tế bào ung thư dạ dày MKN45: (A) Hình thái tumorsphere; (B) Số lượng tumorsphere và (C) Kích thước tumorsphere; $n=5,{ }^{*} \mathrm{p} \leq 0,0001$. $\# \mathrm{p} \leq 0,05$; $\$ \mathrm{p} \leq 0,01$ (so với nhóm nồng độ 5 và $10 \mu \mathrm{M}$ ); NS: không có sự khác biệt. Thang đo: $200 \mu \mathrm{m}$.

giá tác động của curcumin lên các tumorsphere đã được hình thành sau 5 ngày nuôi cấy (chưa xử lý với curcumin) như trong mô tả mục 2.5.3. Kết quả đánh giá được trình bày trong Hình $3 \mathrm{~A}$ và Hình $3 \mathrm{~B}$ cho thấy rằng, ở nồng độ thấp $5 \mu \mathrm{M}$, curcumin không làm giảm số lượng tumorsphere so với đối chứng mặc dù ở nồng độ này nó đã ức chế số lượng tumorsphere được hình thành từ các tế bào đơn (Hình 2B). Tuy nhiên ở các nồng độ cao hơn, từ $10 \mu \mathrm{M}$ đến $20 \mu \mathrm{M}$, curcumin đã làm giảm rõ rệt số lượng tumorsphere. Quan sát dưới kính hiển vi độ phóng đại từ 200 lần đã cho thấy, curcumin đã làm tan rã các khối tế bào thành những tế bào đơn và hình dạng của khối tế bào chết xuất hiện trong các sphere bị xử lý với curcumin. Kết quả nghiên cứu này đã chỉ ra rằng, curcumin không chỉ tác động trực tiếp lên các tế bào đơn trong nuôi cấy một lớp (2D) hoặc nuôi cấy tạo tumorsphere từ các tế bào đơn $(3 \mathrm{D})$ mà nó còn tác động lên cả khối tế bào (tumorsphere) về số lượng và kích thước. Điều này có ý nghĩa quan trọng để tiến tới các thử nghiệm in vivo. 
Trước đó, chúng tôi đã chứng minh rằng ATRA, một chất ức chế tế bào gốc ung thư dạ dày tiềm năng đã tiêu diệt các tumorsphere ở nồng độ từ $5-10 \mu \mathrm{M}[13]$. Có thể nói rằng, nuôi cấy các tumorsphere hay còn gọi là các spheroid là một mô hình vượt trội so với nuôi cấy $2 \mathrm{D}$ trong việc nghiên cứu phát triển thuốc [21]. Thakuri và cộng sự đã chỉ rằng, việc xử lý các tumorsphere của ung thư đại tràng bởi chất ức chế MEK phối hợp với các chất ức chế con đường tín hiệu ung thư đã làm giảm khả năng kháng lại các chất ức chế MEK [22].

Không chỉ vậy, nuôi cấy các tumorsphere 3D cũng được đánh giá là một mô hình có vi môi trường gần giống với in vivo và được áp dụng để đánh giá ảnh hưởng của phương pháp xạ trị lên tế bào ung thư [23].

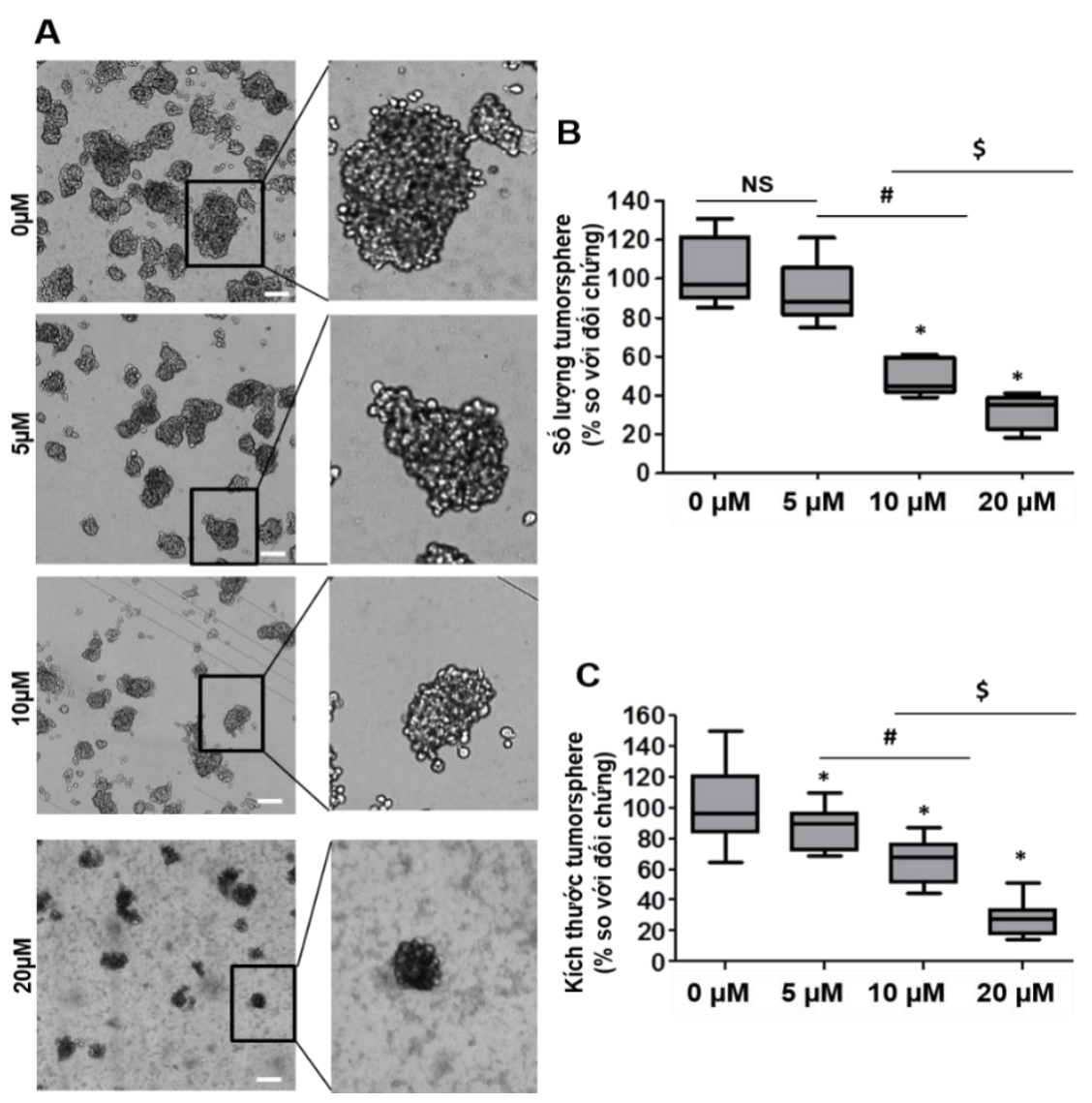

Hình 3. Ảnh hưởng của curcumin lên sự hình sự tăng trưởng tumorsphere của tế bào ung thư dạ dày MKN45:

(A) Hình thái tumorsphere; (B) Số lượng tumorsphere và (C) Kích thước tumorsphere; $\mathrm{n}=5,{ }^{*} \mathrm{p} \leq 0,0001$. \# $\mathrm{p} \leq$ 0,$05 ; \$ \mathrm{p} \leq 0,01$ (so với nhóm nồng độ 5 và $10 \mu \mathrm{M}$ ). Thang đo: $200 \mu \mathrm{m}$.

\section{Kết luận}

Trong nghiên cứu này, chúng tôi đã chỉ ra rằng, curcumin là một chất có khả năng tác động trực tiếp lên các đặc tính của tế bào gốc ung thư dạ dày. Curcumin đã điều hòa giảm mạnh số lượng các tế bào biểu hiện marker của tế bào gốc ung thư dạ dày CD44. Phân tích trong điều kiện nuôi cấy $3 \mathrm{D}$ đã cho thấy rằng, curcumin không chỉ ức chế mạnh sự hình thành các tumorsphere từ các tế bào ung thư dạ dày mà nó còn làm giảm kích thước của các tumorsphere được hình thành. Đáng chú ý, curcumin còn có khả năng làm tan rã và gây chết các tumorsphere dẫn tới giảm rõ rệt về số lượng và kích thước của các tumorsphere. 


\section{Tài liệu tham khảo}

[1] F. Bray, J. Ferlay, I. Soerjomataram, R.L. Siegel, L.A. Torre, A. Jemal, Global cancer statistics 2018: GLOBOCAN estimates of incidence and mortality worldwide for 36 cancers in 185 countries, CA Cancer J Clin 68 (2018) 394-424. https://doi.org/10.3322/caac.21492.

[2] Z. Yu, T.G. Pestell, M.P. Lisanti, R.G. Pestell, Cancer stem cells, Int J Biochem Cell Biol 44 (2012) 2144-51. https://doi.org/10.1016/j.biocel. 2012.08.022.

[3] M. Shibata, M.O. Hoque, Targeting Cancer Stem Cells: A Strategy for Effective Eradication of Cancer, Cancers (Basel) 11 (2019). https://doi. org/10.3390/cancers11050732.

[4] H. Hatcher, R. Planalp, J. Cho, F.M. Torti, S.V, Torti, Curcumin: from ancient medicine to current clinical trials, Cell Mol Life Sci 65 (2008) 1631 52.https://doi.org/10.1007/s00018-008-7452-4.

[5] J. Ravindran, S. Prasad, B.B. Aggarwal, Curcumin and cancer cells: how many ways can curry kill tumor cells selectively? AAPS J 11 (2009) 495510.https://doi.org/10.1208/s12248-009-9128-x.

[6] S. Zhou, D. Yao, L. Guo, L. Teng, Curcumin suppresses gastric cancer by inhibiting gastrinmediated acid secretion, FEBS Open Bio 7 (2017) 1078-84.https://doi.org/10.1002/2211-5463.12237.

[7] M. Jakubek, Z. Kejík, R. Kaplánek, R. Hromádka, V. Šandriková, D. Sýkora, et al, Strategy for improved therapeutic efficiency of curcumin in the treatment of gastric cancer, Biomedicine \& Pharmacotherapy 118 (2019) 109278.https://doi. org/10.1016/j.biopha.2019.109278.

[8] Y. Li, T. Zhang, Targeting cancer stem cells by curcumin and clinical applications, Cancer Letters 346 (2014) 197-205.https://doi.org/10.1016/j.can let.2014.01.012.

[9] W.T. Kim, C.J. Ryu, Cancer stem cell surface markers on normal stem cells, BMB Rep 50 (2017) 285-98.https://doi.org/10.5483/bmbrep.2017. 50.6.03.

[10] P.H. Nguyen, J. Giraud, L. Chambonnier, P. Dubus, L. Wittkop, G. Belleannée, et al, Characterization of Biomarkers of Tumorigenic and Chemoresistant Cancer Stem Cells in Human Gastric Carcinoma, Clin Cancer Res 23 (2017) 1586-97.https://doi.org/10.1158/1078-0432. CCR $-15-2157$
[11] S. Misra, V.C. Hascall, R.R. Markwald, S. Ghatak, Interactions between Hyaluronan and Its Receptors (CD44, RHAMM) Regulate the Activities of Inflammation and Cancer, Front Immunol6(2015). https://doi.org/10.3389/fimmu. 2015.00201

[12] S. Takaishi, T. Okumura, S. Tu, S.S.W. Wang, W. Shibata, R. Vigneshwaran, et al, Identification of gastric cancer stem cells using the cell surface marker CD44, Stem Cells 27 (2009) 100620.https://doi.org/10.1002/stem.30.

[13] P.H. Nguyen, Giraud J, C. Staedel, L. Chambonnier, P. Dubus, E. Chevret, et al, Alltrans retinoic acid targets gastric cancer stem cells and inhibits patient-derived gastric carcinoma tumor growth, Oncogene 35 (2016) 561928.https://doi.org/10.1038/onc.2016.87.

[14] P.H. Nguyen, J. Giraud, C. Staedel, L. Chambonnier, P. Dubus, E. Chevret, et al, Alltrans retinoic acid targets gastric cancer stem cells and inhibits patient-derived gastric carcinoma tumor growth, Oncogene 35 (2016) 561928.https://doi.org/10.1038/onc.2016.87.

[15] S. Takaishi, T. Okumura, S. Tu, S.S.W. Wang, Shibata W, Vigneshwaran R, et al, Identification of Gastric Cancer Stem Cells Using the Cell Surface Marker CD44, Stem Cells 27 (2009) 1006-20.https://doi.org/10.1002/stem.30.

[16] P.H. Nguyen, J. Giraud, L. Chambonnier, P. Dubus, L. Wittkop, G. Belleannée, et al, Characterization of Biomarkers of Tumorigenic and Chemoresistant Cancer Stem Cells in Human Gastric Carcinoma, Clin Cancer Res 23 (2017) 1586-97.https://doi.org/10.1158/1078-0432.CCR $-15-2157$.

[17] W. Quarni, R. Dutta, R. Green, S. Katiri, B. Patel, S.S. Mohapatra, et al, Mithramycin A Inhibits Colorectal Cancer Growth by Targeting Cancer Stem Cells, Sci Rep 9 (2019) 15202. https://doi.org/10.1038/s41598-019-50917-3.

[18] L. Yang, P. Shi, G. Zhao, J. Xu, W. Peng, J. Zhang, et al, Targeting cancer stem cell pathways for cancer therapy, Signal Transduct Target Ther 5 (2020) 8.https://doi.org/10.1038/s41392-0200110-5.

[19] V. Laszlo, Z. Valko, J. Ozsvar, I. Kovacs, T. Garay, M.A. Hoda, et al, The FAK inhibitor BI 853520 inhibits spheroid formation and orthotopic tumor growth in malignant pleural 
mesothelioma, J Mol Med 97 (2019) 23142.https://doi.org/10.1007/s00109-018-1725-7.

[20] S. Courtois, R.V. Durán, J. Giraud, E. Sifré, J. Izotte, F. Mégraud, et al, Metformin targets gastric cancer stem cells, Eur J Cancer 84 (2017) 193-201.https://doi.org/10.1016/j.ejca.2017.07. 02.

[21] C.H. Lee, C.C. Yu, B.Y. Wang, W.W. Chang,Tumorsphere as an effective in vitro platform for screening anti-cancer stem cell drugs, Oncotarget 7 (2016) 1215-26.https://doi.org/10. 18632/oncotarget.6261.
[22] P. Shahi Thakuri, G.D. Luker, H. Tavana, Cyclical Treatment of Colorectal Tumor Spheroids Induces Resistance to MEK Inhibitors, Transl Oncol 12 (2019) 404-16. https://doi.org/ 10.1016/j.tranon.2018.11.009.

[23] S.C. Brüningk, I. Rivens, C. Box, U Oelfke, G. ter Haar, 3D tumour spheroids for the prediction of the effects of radiation and hyperthermia treatments, Sci Rep 10 (2020) 1653. https:// doi.org/10.1038/s41598-020-58569-4. 